\title{
Sociedade do consumo e o papel da educação
}

\author{
Maria de Fátima Ramos de Andrade ${ }^{1}$ \\ Gabriel Zecchin²
}

\section{Resumo}

Aparentemente, o consumo é encarado pela sociedade atual como algo banal, corriqueiro e extremamente comum, afinal diariamente realizamos tal atividade, sem planejamento prévio e reconsideraçóes. O presente artigo tem como objetivo discutir o conceito de consumo e consumismo na sociedade atual, apontando os impactos do ato de consumir na vida dos indivíduos e o papel da educação frente ao comportamento consumista. Para tal, recorremos aos estudos de Zigmunt Bauman, Benjamin R. Barber, Lívia Barbosa e Paulo Freire. A intençáo é contribuir para um consumo consciente que vise a mudança da sociedade, rompendo com o paradigma do consumismo e da inversão do "ser" pelo "ter".

Palavras-chave: Consumo. Consumismo. Educação. Escola.

\begin{abstract}
Apparently, society sees consumerism as something trivial, unexceptional and extremely common. After all, we consume different things every day, without previous planning or considerations. The objective of the present article is to discuss the concepts of consumption and consumerism in our current society, showing the impacts of consumption in people's lives, as well as to discuss the role of education when dealing with consumerist behaviour. To meet such an objective, we resort to studies written by Zigmunt Bauman, Benjamin R. Barber, Livia Barbosa and Paulo Freire. The intention is to contribute to conscious consumption that aims at changing society, thus breaking the paradigm of consumerism and the current version of "having" instead of "being".
\end{abstract}

Keywords: Consumption. Consumerism. Education. School.

\footnotetext{
${ }^{1}$ Pós-doutora em Educação pela Fundação Carlos Chagas; Doutora em Comunicação e Semiótica pela PUC/SP. É professora do Programa de Pós-graduação Stricto Sensu em Educação, Arte e História da Cultura da Universidade Presbiteriana Mackenzie, Professora do Curso de Pedagogia da USCS e Profa. Colaboradora do Mestrado Profissional em Educação da Universidade Municipal de São Caetano do Sul. E-mail: <mfrda@uol.com.br>.

${ }^{2}$ Mestre em Educação, Artes e História da Cultura pela Universidade Presbiteriana Mackenzie, é professor de História no Colégio Santa Maria e em Escola de Ensino Fundamental II e Médio da rede municipal de São Paulo. E-mail: <gabriel_zecchin@hotmail.com>.
} 
Introdução

Nesse texto apresentamos os conceitos de consumo, consumismo e de educação. Para tal, tomamos como referência os estudos de Bauman (2008), Barbosa (2004), Guerra (2010), Strapazzon e Machado (2012) e Freire (1967), lembrando que educação pode ser tanto um instrumento de reproduçáo do status quo e das desigualdades existentes na sociedade quanto uma possibilidade de romper com o paradigma consumista atual.

\section{Conceito de consumo e consumismo}

Para a discussão proposta nesse artigo é imprescindível a distinção entre "consumo" e "consumismo". É por meio dessa compreensão que conseguiremos entender algumas das transformaçóes pelas quais a sociedade capitalista passou ao longo de sua história: de uma "[...] perspectiva individualista - o ato de consumir - para uma perspectiva social - a de uma sociedade que se constitui tendo o consumo como papel determinante na organização de sua vida social” (GUERRA, 2010, p.10).

Contudo, antes de chegarmos às definições de consumo e consumismo, é também de suma importância apontar que na sociedade contemporânea, a atividade do consumo está normatizada e internalizada no comportamento humano, sendo tratada como algo banal, até mesmo sem importância. De fato, o consumo não é uma atividade moderna e, como afirma Bauman (2008, p.37), é uma “[...] condição, e um aspecto permanente e irremovível, sem limites temporais ou históricos; um elemento inseparável da sobrevivência biológica que nós humanos compartilhamos com todos os outros organismos vivos".

Segundo esse pressuposto é fácil imaginar que o fenômeno do consumo está presente na história humana, mas não podemos negar que em determinado momento ocorreu uma ruptura de grandes consequências, que levou a sociedade entáo existente à sociedade do consumo. O que sabemos é que não existem registros específicos e pontuais em torno do "quando" a sociedade do consumo tem seu início. Alguns teóricos apontam uma variação do século XVI até o XVIII.

O que se sabe de fato é que esse período de ruptura, ou como Bauman (2008) chama, a "revolução consumista" e, Babosa (2004), a "revolução do consumo", sem dúvida precedeu a Revolução Industrial, ao contrário do que se pensou por muito tempo pela historiografia tradicional, mas sem retirar a importância desse evento como elemento indispensável da modernidade, especificamente, da sociedade ocidental. Nesse sentido, precisamos pontuar que:

As grandes invençóes tecnológicas que estão associadas à Revolução Industrial ocorreram muito tempo depois dessa explosão do consumo [...] As principais invençốes mecânicas da indústria de tecidos, cabeça de lança da industrialização, só apareceram a partir da década de 1780, embora a indústria de roupas já funcionasse a pleno vapor, fundada no trabalho externo ou doméstico dos artesões, permanecendo com essa estrutura produtiva até a década de 1830. O mesmo se refere à indústria de brinquedos, cujas inovações tecnológicas só vieram a afetá-la depois de plenamente estabelecida. Podemos concluir, portanto, que não foram 
essas invençôes que criaram as condiçôes matérias para as pessoas consumirem mais (BARBOSA, 2004, p.16).

Embora ainda permaneça as incertezas em torno do "quando", é evidente que mudanças significativas afetaram a quantidade de itens disponíveis para o consumo assim como as variedades disponíveis. Tais mudanças se devem ao período de espação do comércio europeu ao oriente, estabelecendo uma relação de comércio que vai ampliar a oferta e consequentemente a demanda por novas mercadorias, as chamadas "especiarias". Segundo Barbosa (2004, p.19) foi "a partir do século XVI, registra-se o aparecimento de todo um conjunto de novas mercadorias no cotidiano dos diversos segmentos sociais, fruto da expansão ocidental para o oriente" (BARBOSA, 2004, p.19).

Neste momento de predominância do comércio entre oriente e ocidente, as sociedades tradicionais produziam bens de consumo, para atender suas próprias necessidades, de forma previamente definida, os grupos sociais possuíam estilos de vida, que estavam ligados e dependentes de status, "[...] isto quer dizer que a posiçâoo social de uma pessoa determinava o seu estilo de vida, independentemente da sua renda, ou seja das condições objetivas que esta pessoa possuía para mantê-lo" (BARBOSA, 2004, p.20).

Contudo, na sociedade contemporânea capitalista, esse engessamento do estilo de vida a classe social que os indivíduos estavam presos é quebrado, uma vez que sua principal característica é o individualismo. Esse, fruto das relaçóes existentes dentro do mercado de trabalho, se apresenta como mais um dos mercados de produtos em que todas as pessoas estão inseridas e disputam entre elas um espaço. "Para tanto, fazem o máximo possível e usam os melhores recursos que têm à disposição para aumentar o valor de mercado dos produtos que estáo vendendo. E os produtos que são encorajadas a colocar no mercado, promover e vender são elas mesmas." (BAUMAN, 2008, p.13). Assim temos uma sociedade na qual os indivíduos estão o todo tempo investindo em si próprios para se destacaram e diferenciarem, buscando se tornarem ao mercado de trabalho, por exemplo, os mais vendáveis possíveis, com mais atributos e qualificaçóes, ou seja, mercadorias melhores a serem "compradas".

De acordo com Bauman (2008), esse processo descrito acima, a transformaçáo dos consumidores em mercadorias, é considerado a característica mais proeminente da sociedade de consumidores - ainda que cuidadosamente disfarçada e encoberta. Pois é evidente que os indivíduos estáo naturalizados com esse processo a tal ponto que não estranham essa relação de não serem apenas consumidores de mercadorias, mas também mercadoria.

Essa naturalizaçáo por parte dos indivíduos se deve em nossa sociedade porque o consumo, no mundo moderno, "[...] ]se tornou o foco central da vida social. Práticas sociais, valores culturais, ideias, aspirações e identidades são definidas e orientadas em relação ao consumo." (BARBOSA, 2004, p.32), transformando então, as vontades e desejos nas forças que movem e operam a sociedade capitalista contemporânea. Vivemos um momento histórico que o consumo permeia a vida social dos indivíduos, tudo acaba girando em torno do que a pessoa consome, de quais bens de consumo ela possui e de quanto ela consegue se diferenciar dos outros por meio de ambos. "Identificando-o como fato socialmente construído através do qual os grupos sociais se classificam, se distinguem e se comunicam." (GUERRA, 2010, p.24). 
Afinal de contas o consumo expressa a individualidade das pessoas, sua auto expressão, estilo e evidentemente confere status a elas dentro da sociedade. Tudo por meio da "roupa, o corpo, o discurso, o lazer, a comida, a bebida, o carro, a casa. [...] Os objetos e as mercadorias são utilizados como signos culturais." (BARBOSA, 2004, p.23). Deveríamos encarar o consumo então, como uma consequência de uma multiplicidade de mudanças sociais que marcaram de forma profunda o mundo ocidental, da qual fazemos parte.

Dado contexto descrito, nos deparamos então com uma sociedade capitalista, na qual o mercado tem a capacidade de dominar a vida do indivíduo, culminando em sua alienação frente a realidade. Isso é possível pois o "mercado de consumo é ubíquo (está em toda a parte); é onipresente (está 'o tempo todo' e aspira a preencher todo o tempo); é viciante (cria suas próprias formas de reforço); é auto-reprodutivo (espalha-se de maneira viral); e é onilegítimo (entrega auto-racionalização e autojustificação, destruindo as bases morais para resistir a ele)" (BARBER, 2009, p.250-251).

Tal mercado de consumo descrito anteriormente só existe por conta da produção em larga escala, que produz, muito mais do as pessoas necessitam, provocando um processo que visa a desvalorização tanto dos bens de consumo como dos produtores e consumidores. Vivemos assim em uma sociedade na qual o ciclo da vida, segundo Barber (2009), gira em torno de "ter, produzir e consumir". Ficando evidente cada vez mais que estamos inseridos atualmente em uma espécie de jogo das marcas que "tem como alvo os consumidores, mas também ajuda a apagar as fronteiras entre o consumidor e o que é consumido. Pensando que conquistou o mundo das coisas, o consumidor é, na verdade consumido por essas coisas" (BARBER, 2009, p.47).

É importante ressaltar que "o consumismo associa a felicidade não tanto à satisfação de necessidades [...] mas a um volume e uma intensidade de desejos sempre crescentes, o que por sua vez implica o uso imediato e a rápida substituição dos objetos destinados a satisfazê-la” (BAUMAN, 2008, p.44). Ou seja, a pura busca pela satisfação de nossos desejos de consumo que em tese trará aos indivíduos uma felicidade. Tal sentimento de felicidade é totalmente momentâneo, uma vez que sabemos do grande fluxo de mercadorias na atualidade e da necessidade constante do mercado de consumo, que os indivíduos nunca parem de consumir, logo quando um desejo é satisfeito e as pessoas acreditam que estão mais felizes, por terem mais um objeto de consumo, novos desejos/ necessidades, aparecerem quase que de imediato para estimular novamente essa pessoa ao consumo. Desta forma é fácil imaginar que essa busca pela felicidade, leva os indivíduos em sua grande maioria, à uma existência na qual nunca estão completos, satisfeitos e felizes, mas estão buscando ambas por meio do consumo ininterrupto.

Assim, chegamos ao conceito fundamental desse artigo, o "consumismo" que pode ser definido como um arranjo social que provoca uma ávida disputa entre os indivíduos pela sonhada diferenciação social, pois agora as "necessidades" mudam conforme o estilo, a variedade e disponibilidade das mercadorias existentes. Assim, atualmente é imprescindível a substituição ininterrupta dos bens de consumo, para que preservem seu caráter simbólico de atribuição de status, assim é necessário estimular o desejo de consumo nos indivíduos. Tais desejos deveriam ser realizados para que as pessoas assim alcancem a diferenciação social que buscam e com elas agregam a si próprias no meio social o status tanto almejado.

Resultante da reciclagem de vontades, desejos e anseios humanos rotineiros, permanentes e, por assim dizer, "neutros quanto ao regime", transformando-os na principal força propulsora e operativa da sociedade, uma força que coordena a 
reprodução sistêmica, a integração e a estratificação sociais, além da formaçáo de indivíduos humanos, desempenhando ao mesmo tempo um papel importante nos processos de auto identificação individual e de grupo, assim como na seleção e execução de políticas de vida individuais (BAUMAN, 2008, p.41).

É exatamente por essas razóes que a sociedade atual, possui uma constante vontade de adquirir e juntar, entretanto o que realmente se evidencia é a pressa e a "necessidade de descartar e substituir" (BAUMAN, 2008 , p.50). Não se pode negar que esse ciclo vicioso da produção em massa e consequentemente do consumo em massa, baseado em uma vida "agorista", os indivíduos buscam uma satisfação instantânea e completa, mas quando os supostos objetos desejados já não mais os satisfazem, devem ser abandonados.

O consumismo em massa está intrinsicamente ligado ao sentimento de insaciabilidade dos consumidores, "assim que um desejo ou "necessidade" é satisfeito, outro já se acha à espera. Esse processo é incessante e ininterrupto" (BARBOSA, 2004, p.50). É possível compreender que para os indivíduos o ato do consumo provoca um sentimento de liberdade e privado, afinal todos são livres para escolher o querem comprar, quando comprar e como irão pagar, a vista a prazo e etc.

Nesse processo de busca pela felicidade de satisfação de desejos, é fácil perceber que a cultura do consumo possui como seu pilar fundamental comprar, ou seja, o consumo, por isso, as novidades se tornam a todo instante obsoletas, ultrapassadas e descartáveis, afinal de contas esse ciclo de consumo, descarte, desejar e consumir novamente, nunca pode ser encerrado. Para sustentar esse ciclo é de grande importância que a sociedade de consumo mostre aos indivíduos que:

O valor do ser humano está no consumir e não mais na sua moral, nos seus atos, no seu amor, ou seja, o poder de consumo dita as novas regras sociais. Quem consome mais tem mais valor. Assim, quanto maior for a população de excluídos melhor será o status do grande consumidor (PEREIRA; HORN, 2009, p.18).

Por conseguinte, é inegável e evidente que a sociedade de consumidores não faz distinção alguma muito menos diferenciação de gênero e idade, tampouco de classe social, afinal de contas o consumo se trata de uma vocação, ligada, por fim, aos desempenhos individuais de todos os indivíduos que compõe a sociedade. Essa questão do status é de suma importância pois não podemos perder de vista que "consumir, portanto, significa investir na afiliaçấo social de si próprio, o que, numa sociedade de consumidores, traduz-se em "vendabilidade", obter qualidades para as quais já existe uma demanda de mercado, ou reciclar as que já se possui" (BAUMAN, 2008, p.75).

Cabe então refletir a respeito do papel dos indivíduos na sociedade atual, uma vez que, segundo Bauman (2008, p.83), são todos, do berço ao túmulo, consumidores, que vivem suas vidas sob um mecanismo de comodificação, isso é, o consumo pensado como uma tarefa que a muito foi socialmente empreendida e administrada. Tarefa essa vista como um investimento em tudo que os leve ao "valor social". 
Fica evidente então que os objetos de consumo, se caracterizam assim como símbolos de "ascensão social, salvo-conduto para atravessar as alfândegas da sociedade de classes, chaves que abrem portas proibidas. Quanto mais exclusivas, melhor: as coisas te escolhem e te salvam do anonimato multitudinário." (GALEANO, 2009, p.267). Neste sentido o consumidor é indubitavelmente a base da economia capitalista, afinal de contas ele é o responsável pela mesma. Essa responsabilidade e dever que é imposto a todos os indivíduos, o de consumir, provocou, sem sombra de dúvidas, profundas mudanças nos modos de vida.

Uma delas é a vida hedonista, agarrada aos prazeres imediatos. Por ela, a população se preocupa em satisfazer agora, sem preocupaçóes futuras. Uma população hedonista consumirá mais para se satisfazer e consumirá o mais rapidamente possível, e depois procurará outro produto para consumir e se satisfazer novamente (PEREIRA; HORN, 2009, p.14).

Desta forma, como o objetivo é sempre continuar consumindo, os objetos possuem signos, pois estes são utilizados como comunicadores e não apenas por sua utilidade aos indivíduos. Nesse sentido, "o valor dos bens depende mais do seu valor cultural (de signo) do que do seu valor de uso ou de troca" (BARBOSA, 2004, p.35). Dessa maneira, o signo é a mercadoria, logo a atividade de consumo, segundo Bauman (2008, p.41), é a "principal força propulsora e operativa da sociedade".

Quando lecionava em uma escola pública municipal no bairro do Campo Belo na Zona Sul de São Paulo, notei entre os jovens alunos, o status social que alguns celulares causavam, chamavam a atenção de todos, todos os alunos sabiam quem eram os alunos que tinham determinado celular, e os donos possuíam uma certa popularidade entre o grupo. Era muito comum ver outros jovens pedindo para manusear, jogar jogos, ouvir música e etc. Era visível que o aparelho promovia o estabelecimento de relaçóes sociais, outros jovens tentavam competir com outros celulares considerados bons também pelo grupo, falam das qualidades entre eles, das desvantagens e por fim era possível notar que existia um sentimento de pertencimento de grupo se você possui-se um smartphone, pois os que não tinham condição ficavam a mercê dos que possuíam, desejavam possui-los, e até eram ridicularizados por não terem um aparelho de celular, ou até por terem aparelhos considerados inferiores.

Desta forma é inegável que os indivíduos circunscritos no processo descrito anteriormente, fazem uso da cultura material "para fins estritamente simbólicos e utilizar objetos e mercadorias como diferenciadores ou comunicadores sociais é um processo utilizado em todas as sociedades" (BARBOSA, 2004, p.43). Entretanto é inegável que na sociedade capitalista contemporânea esse materialismo foi levado a um ponto jamais visto antes, pois atualmente, o consumo é visto e tratado "como vocação e é ao mesmo tempo um direito e um dever humano universal que não conhece exceçâo" (BAUMAN, 2008, p.73). Neste sentido nesse modelo de sociedade o "desempenho consumista se transforma no principal fator de estratificaçáo e no maior critério de inclusão e exclusão, assim como orientam a distribuição do apreço e do estigma sociais, e também de fatias da atenção do público" (BAUMAN, 2008, p.71).

Porém, é importante destacar que nem todos os indivíduos de nossa sociedade tem o mesmo poder de consumo, devido a inúmeros aspectos de suas vidas socioeconômicas, que dentro do sistema econômico 
capitalista, são absurdamente desiguais. Sabendo disso adicionando que "o valor do ser humano está no consumir e não mais na sua moral, nos seus atos, no seu amor, ou seja, o poder de consumo dita as novas regras sociais. Quem consome mais tem mais valor." (PEREIRA \& HORN, 2009, p.16). Temos aqui um dos grandes problemas do mundo contemporâneo baseado no modo de vida consumista:

Embora a modernidade tenha prometido a todos a felicidade por meio do consumo, é indiscutível que nem todos têm acesso aos produtos colocados no mercado, surgindo populaçóes excluídas dessa economia: populaçóes que desejam os produtos, mas jamais os terão. Populaçóes estas que, pela subjetividade, acreditam ser capazes de, em algum dia, consumir. Em outras palavras acreditam que, em algum dia, poderão existir já que, em nossa sociedade, quem não consome não existe. A subjetividade mantém a esperança dessas pessoas, para que elas não se revoltem e aceitem seu estado de vida por mais degradante que seja. Afinal, lamentavelmente, essas pessoas são necessárias para a sociedade de consumo, como mão de obra barata e, também para estabelecer um abismo diferenciador entre elas e os que consomem. Abismo este criador do status social. (PEREIRA; HORN, 2009, p.16).

Assim, em nossa sociedade, a ostentação e o direito de consumir de forma esbanjada, segundo Galeano (2009, p. 266), é “[...] privilégios de poucos, quer significar a liberdade para todos". Afinal de contas o desejo pelo consumo será inculcado na grande massa de indivíduos, por meio da publicidade, pois “[...] qualquer pessoa entende, em qualquer lugar, as mensagens que o televisor transmite. No último quarto de século, os gastos de publicidade duplicaram no mundo. [...]. Comprado a prazo, este animalzinho prova a vocação democrática do progresso: não escuta ninguém, mas fala para todos.” (GALEANO, 2009, p.266).

Sabemos que a publicidade deveria proporcionar sempre a ampliação do número de consumidores ao mercado, sendo assim é possível identificar que o mercado infantiliza os indivíduos da sociedade, para que tenham atitudes impulsivas ao consumirem. Contudo, muitos não possuem em tese o poder de consumo, entretanto foi oferecido a estes uma possibilidade de também realizarem seus desejos de consumos e comprarem bens de consumo que agreguem status e valor a suas vidas. Assim para estes "a sociedade de consumo aumenta o potencial consumidor através dos cartóes de crédito, que propiciam ao indivíduo a satisfação imediatamente das suas necessidades." (ROSSONI, 2010, p.14).

Dessa forma temos uma grande parcela da população que em busca da satisfação de seus desejos e a procura pela felicidade, que aliás, "[...] não é um valor cultural, ela triunfa no reino das ideais, é um produto que todos podem ter." (ROSSONI, 2010, p.15). Chegamos à dura conclusão que a cultura do consumo vigente atualmente fez da sociedade o mais lucrativo dos mercados.

Por fim, é nessa sociedade que mais se assemelha a um mercado que as crianças crescem e são educadas, sendo também mais um alvo da cultura consumista, pois "[...] a criança quer sem refletir, sem considerar as necessidades dos outros, ou os próprios limites." (ROSSONI, 2010, p.14). Neste sentido as crianças como sujeitos portadores de direitos, são transformados em consumidores o mais cedo possível. Barber (2009, 
p.31) apresenta que nesse movimento de cativar a criança a publicidade tenta a todo custo "[...] capturar a imaginação das crianças e prendê-las ao mercado". É importante assim ressaltar que "[...] a participação das crianças como atores no mundo dos produtos, como pessoas dotadas de desejo, fornece uma base ao atual e emergente status delas como indivíduos portadores de direitos" (BAUMAN, 2008, p.84).

Neste sentido, ao resgatar o Estatuto da Criança e do Adolescente - ECA (Brasil, 1990) podemos ver que este prevê o respeito aos direitos das crianças e dos jovens com a premissa máxima de salvaguardar seu desenvolvimento integral, incluindo-se não apenas as necessidades básicas de saúde, lazer, educação, mas também de compreender a inserção social e cultural de tais crianças e adolescentes que crescem num país emergente como o Brasil, inseridas num sistema capitalista que induz ao consumo exacerbado.

Esse novo habitat está baseado na cultura consumista, da sociedade de consumo, sociedade que internaliza e naturaliza o consumo a tal ponto que todos os indivíduos nascem e são criados sob uma perspectiva de que precisam ser alguém, devem ser alguém e tem acima de tudo que ser um "consumidor por vocação" como destaca Baumam (2008, p.73). Assim, não se pode esquecer que as crianças estão envolvidas, recebendo influências e pressões, desde muito cedo, por essa cultura consumista que estabelece que todos os indivíduos devem ser consumidores e devem consumir, exercendo esse movimento como um hábito natural que sempre foi assim e que sempre será. "Nessa sociedade, o consumo visto e tratado como vocação é ao mesmo tempo um direito e um dever humano universal que não conhece exceçáo" (BAUMAN, 2008, p.73).

Por fim, frente a essa realidade consumista a que todos os indivíduos estáo submetidos, e tratados como consumidores por vocação, indivíduos que possuem não apenas o direito ao consumo, mas também lhe são impostos o dever de consumirem, se faz necessário pensar qual o papel da educação nesse processo naturalizado e reproduzido atualmente. Devo destacar que a escola é uma instituição que pode ser usada como um instrumento de reprodução do status quo da sociedade vigente, assim como, pode ser uma instituição que funcione como contracultura, uma possibilidade de estranhamento a tal naturalização da realidade e que promova a todos os indivíduos uma tomada de consciência crítica, que possibilite assim a transformação de suas vidas e da realidade social na qual estão inseridos.

Não deveríamos gerir um mundo na qual as crianças nascem e são criadas pensando em dinheiro, valorizando bens de consumo e dando mais importância ao "ter" do que verdadeiramente ao "ser". Deveríamos promover uma mudança nesse paradigma consumista que está posto e enraizado em nossa sociedade. Deveríamos contrapor essa naturalização de comportamento, em que os bens de consumo, diferenciam os indivíduos e lhes concedem status social, no qual os indivíduos se tornam escravos do consumismo, pois sempre estáo buscando atingir a felicidade de serem reconhecidos socialmente e de possuírem um status que os diferencie dos demais.

Deveríamos gerir um mundo que tenha uma escola/ educação que proporcionasse um processo de libertação dos indivíduos. Para isso é de suma importância analisar quais estão sendo as açôes dos docentes frente a essa realidade, se eles próprios possuem consciência desse processo inculcado nos indivíduos desde muito cedo e camuflado pela sociedade capitalista. Afinal de contas já temos o conhecimento que não é possível, ambientalmente falando, continuar com esse estilo de vida da produção em massa, do consumo em massa e do descarte em massa, pois estamos destruindo a natureza por todo o processo de produçáo venda e 
descarte desses bens de consumo que se tornaram o grande foco da vida. A uma tomada de consciência dos indivíduos é indubitavelmente essencial para mudarmos o nosso futuro e garantirmos um planeta melhor e uma vida melhor em sociedade para as futuras geraçôes.

\section{0 conceito de educação e o consumismo}

Tendo em vista as implicaçôes do consumo na sociedade contemporânea capitalista analisadas até aqui, passaremos ao conceito de educação. Cabe lembrar que a educação pode ser tanto um instrumento de reprodução do status quo e das desigualdades existentes na sociedade, como uma possibilidade de romper com o paradigma consumista atual, na qual todos os indivíduos estão submersos, fornecendo a possibilidade para que os mesmos tomem uma consciência do que poderia ser um consumo consciente.

Assim para analisar a educação que queremos, é imprescindível retomarmos a realidade que está posta, na qual não importa sua classe social, seu gênero e sua idade, todos nós, vivemos sob a lógica da "sociedade de consumidores" que se "distingue por uma reconstrução das relaçôes humanas a partir do padrão, e à semelhança, das relaçóes entre os consumidores e os objetos de consumo. Os indivíduos nascem e são criados sob uma perspectiva de que precisam ser alguém, devem ser alguém e tem acima de tudo ser um "consumidor por vocação" (BAUMAN, 2008, ps. 19 e 73).

Contudo, a educação deve exercer o papel de contracultura, ou seja, de romper com esse paradigma capitalista, não podemos aceitar uma instituiçấo escolar que apenas reproduza as desigualdades da sociedade capitalista e a naturalização de comportamentos consumistas, transformando os indivíduos em meras mercadorias alienados da realidade contemporânea.

Nesse contexto a educação possui um papel central na formação dos indivíduos, segundo Paulo Freire, ela só alcançará sua efetividade e eficácia se na prática educativa existir a participação livre e crítica dos educandos, afinal de contas a "alfabetização e a conscientizaçăo jamais se separa" (FREIRE, 1967, p.5). A concepção aqui apresentada foi pensada e desenvolvida para um pais considerado de terceiro mundo, repleto de mazelas sociais, políticas e econômicas que atingem grande parte dos brasileiros.

Nesse sentido, uma educaçáo como prática da liberdade, propóe a tomada de consciência: enxergar a realidade para ter chances de mudá-la. Por isso é importante que "[...] o aprendizado das técnicas de ler e escrever ou o das técnicas de manejar o arado ou usar fertilizantes (bem como o aprendizado das ideias de um programa de ação), - enfim, todo aprendizado deve encontrar-se intimamente associado à tomada de consciência da situação real vivida pelo educando." (FREIRE, 1967, p.6).

Desta forma a educação não pode se limitar ao aprendizado de técnicas ou muito menos de noçôes abstratas, já que os adultos e as crianças estão sendo resumidos a "[...] uma infantilização que está intimamente associada às demandas do capitalismo de consumo numa economia de mercado global." (BARBER, 2009, p13.) O aprendizado tem que estar pautado na liberdade e na crítica, para que o educando vá além das relaçóes internas do grupo de aprendizagem e apresente a tomada de consciência de sua realidade social. Assim a visão educacional, discutida até então, "[...] não pode deixar de ser ao mesmo tempo uma crítica da opressão real em que vivem os homens e uma expressão de sua luta por libertar-se." (FREIRE, 1967, p.8). 
A educação deveria proporcionar aos indivíduos a percepção da realidade social. No caso da sociedade atual, baseada na cultura consumista, a insaciabilidade dos consumidores: assim que um desejo é satisfeito, outro já se apresenta a espera de ser realizado.

A educação deveria proporcionar aos indivíduos um processo de estranhamento desse comportamento consumista, por meio de uma tomada de consciência. É importante ressaltar que essa filosofia de educação não propaga a revolta contra a sociedade, assim o termo aqui utilizado, “[...] conscientizar não significa, de nenhum modo, ideologizar ou propor palavras de ordem. Se a conscientização abre caminho à expressão das insatisfaçóes sociais é porque estas são componentes reais de uma situação de opressão." (FREIRE, 1967, p.11).

As Diretrizes Curriculares Nacionais para a Educaçâo Básica apresentam a educação como um elemento que deveria "[...] proporcionar o desenvolvimento humano na sua plenitude, em condiçôes de liberdade e dignidade, respeitando e valorizando as diferenças." (BRASIL, 2013, p.4). Dentro desse projeto educacional vigente atualmente no território nacional, a educação deve ser de qualidade e de direito de todo e qualquer cidadão brasileiro, sem exceção. Segundo o documento, a educação é entendida como:

[...] um direito individual humano e coletivo, implica considerar o seu poder de habilitar para o exercício de outros direitos, isto é, para potencializar o ser humano como cidadão pleno, de tal modo que este se torne apto para viver e conviver em determinado ambiente, em sua dimensão planetária. A educação é, pois, processo e prática que se concretizam nas relaçōes sociais que transcendem o espaço e o tempo escolares, tendo em vista os diferentes sujeitos que a demandam. Educação consiste, portanto, no processo de socialização da cultura da vida, no qual se constroem, se mantêm e se transformam saberes, conhecimentos e valores (BRASIL, 2013, p.16).

Neste sentido só será possível aos indivíduos atuarem na sociedade consumista, visando uma transformação do status quo, se ampliassem conscientização da dinâmica atual. Pois "[...] o opressor mitifica a realidade, e o oprimido a capta de maneira mítica e não critica." (MIZUKAMI, 2013, p.90). De fato, é isso o que ocorre na sociedade atual, uma vez que o consumidor é a base da economia "é ele o indivíduo a ser induzido a carregar a economia consumista. Ele se torna um indivíduo manipulado e, assim, hipossuficiente pela sua falta de conhecimentos tanto sobre o produto quanto sobre seus direitos de consumidor." (PEREIRA; HORN, 2009, p.14).

Frente a essa realidade alienante, a educação aparece como um pilar fundamental no processo de libertação dos indivíduos desse processo naturalizado. Assim é essencial o papel fundamental da educação, como uma possibilidade aos indivíduos desmistificarem essa realidade da sociedade consumista, por meio da "[...] conscientização num processo de tomada de consciência crítica de uma realidade que se desvela progressivamente." (MIZUKAMI, 2013, p.90).

Para isso o teórico Paulo Freire deixa claro em sua obra que a libertação dessa condição de opressão não chegará por acaso e naturalmente, mas sim pela humanização "[...] que supõe a eliminação da opressão desumanizadora, é absolutamente necessário transcender as situaçôes-limite nas quais os homens são reduzidos ao estado de coisas.” (1974 apud MIZUKAMI, 2013, p.90). 
Por esse motivo que dento da perspectiva desse trabalho, a educação é uma possibilidade de retirar os indivíduos desse estado de alienaçáo, no qual o comportamento consumista é naturalizado a tal ponto que a única preocupação de suas vidas é "ter" e não "ser". Os indivíduos imersos nessa realidade são atraídos a todo instante "[..] pelo estilo de vida da sociedade dominante e não se compromete com o seu mundo real. Sua forma de pensar é reflexo do pensamento e expressōes da sociedade dominante." (MIZUKAMI, 2013, p.92).

Por isso o processo de conscientização segundo Mizukami (2013, p.96) “[...] é sempre inacabado, continuo e progressivo, é uma aproximação crítica da realidade”. Assim os indivíduos que passaram pelo ciclo da Educação Básica obrigatória, em nosso país, de nove anos, deveriam possuir a oportunidade de desvelar sua realidade, para que seja capaz de forma consciente de sua realidade e seu papel no mundo, realizar uma reflexão crítica, que leve a transformar não apenas sua realidade, mas a si próprio também. "É preciso que se faça, pois, dessa tomada de consciência, o objetivo primeiro de toda a educação: provocar e criar condiçóes para que se desenvolva uma atitude de reflexão crítica, comprometida com a ação.” (MIZUKAMI, 2013, p.96).

Mas é claro que esse posicionamento em relação a educação não é neutro, afinal o ato pedagógico é um ato político, ou seja, os docentes que fazem parte do processo de ensino aprendizagem não são imparciais em suas açôes, pois como o próprio Paulo Freire (1975, p. 24) apresenta:

Não importa se como educadores somos ou não conscientes, a nossa atividade desenvolve-se ou para a libertação dos homens - a sua humanizaçãoou para a sua domesticação - o domínio sobre eles. [...] Se a minha escolha é a da libertação, a da humanização, é-me absolutamente necessário ser esclarecido de seus métodos, técnicas e processos que tenho de usar quando estou diante dos educandos. Geralmente, pensamos que estamos a trabalhar para os homens, isto é, com os homens, para a sua libertação, para a sua humanização, contudo, estamos a utilizar os mesmos métodos com os quais impedimos os homens de se tornarem livres. Isso se passa desse modo precisamente porque estamos impregnados de mitos que nos tornam incapazes de desenvolver um tipo de ação a favor da liberdade, da libertação. Assim, não é apenas necessário saber que é impossível haver neutralidade da educação, mas é absolutamente necessário definir ambas essas açôes diferentes, antagônicas. Por isso, preciso de analisar, de conhecer, de distinguir esses diferentes caminhos no campo da educação.

\section{Considerações finais}

Cumpre lembrar que o presente texto não possui o discurso de convencer as pessoas a não consumirem, pois, as sociedades sempre consumiram bens que suprissem suas necessidades. O que está em jogo é o comportamento consumista que durante os últimos séculos foi naturalizado nos indivíduos e que se tornou a principal razáo de sua existência. Não podemos mais aceitar que uma vida na qual as pessoas busquem desenfreadamente a felicidade e a realização de seus desejos por meio do consumo 
de bens materiais. Muito menos que mercadorias sejam os elementos de diferenciação social, e que as identidades pessoais sejam formadas por meio da posse ou não dessas mercadorias.

Devemos ter uma educação, que seja uma possibilidade de rompimento com esse paradigma consumista, que promova um estranhamento dessa ânsia incessante de posse, desenvolvem nos indivíduos:

A convicção de que lhes é possível transformar tudo a seu poder de compra. Daí a sua concepção estritamente materialista da existência. O dinheiro é a medida de todas as coisas. E o lucro, seu objetivo principal.

Por isso é que, para os opressores, o que vale é ter mais cada vez mais, à custa, inclusive, do ter menos ou do nada ter dos oprimidos. Ser, para eles é ter e ter como classe que tem. (FREIRE, 1987, p.25).

Se faz necessário, entáo, uma tomada de consciência crítica por parte dos indivíduos dessa realidade opressora a qual estão submetidos, desde muito cedo. Para que dessa forma não coloquem nos objetos a serem consumidos a sua procura pela felicidade e que náo tenham como desejos principais de suas vidas o "ter", possuir mercadorias e bens de consumo, mas sim que seja o "ser". Essa educação deveria romper com as ideias e comportamentos inculcados pelo mundo consumista atual, já analisados anteriormente, a educação deve proporcionar um processo educacional no qual os indivíduos sejam capazes de construir um posicionamento consciente frente as relações de consumo existentes, como a valorização de bens de consumo, busca por status social em objetos de consumo, busca pela felicidade por meio do consumo e a necessidade de estarmos sempre consumindo para nos sentirmos parte dessa sociedade.

Por fim, a educação deveria ser um meio para mudar essa estrutura enraizada na sociedade consumista atual, mas para isso os indivíduos devem tomar consciência de sua realidade, pois a superação "[...] exige a inserçáo crítica dos oprimidos da realidade opressora, com que, objetivando-a, simultaneamente atuem sobre ela" (FREIRE, 1987, p.21) uma vez que tal realidade, já é produto da própria ação dos homens, cabe apenas a eles a tarefa de transformá-la. Por isso que a "práxis" é de suma importância, pois teoria e pratica devem sempre caminhar juntas, de forma indissociável, logo a necessidade do processo de educação como instrumento que possibilite o desenvolvimento de cidadáos conscientes e capazes de atuarem de forma transformadora na sociedade em prol do coletivo, afinal "transformar a realidade opressora é tarefa histórica, é tarefa dos homens" (FREIRE, 1987, p.20).

\section{Referências}

BAUMAN, Zigmunt. Vida para o consumo: a transformação das pessoas em mercadoria. Trad. Carlos Alberto Medeiros. Rio de Janeiro: Zahar, 2008.

BARBER, Benjamin R. Consumido: como o mercado corrompe crianças, infantiliza adultos e engole cidadãos. Tradução; Bruno Casotti. Rio de Janeiro: Record, 2009. 
BARBOSA, Livia. Sociedade de Consumo. Rio de Janeiro: Jorge Zahar Ed., 2004.

FREIRE, Paulo. Educaçáo como Prática da Liberdade. Rio de Janeiro: Paz e Terra LTDA, 1967.

FREIRE, Paulo. Uma Educaçáo para a Liberdade. Porto, Textos Marginais, 1975.

FREIRE, Paulo. Concientización, 1974. In: MIZUKAMI, Maria da Graça Nicoletti. Ensino: as abordagens do processo. São Paulo: E.P.U., 2013. p.90.

GALEANO, Eduardo. De pernas pro ar: a escola do mundo ao avesso. Porto Alegre, RS: L\&PM, 2009.

GUERRA, Renata de Souza. Dimensóes do consumo na vida social. Tese (Doutorado, Universidade Federal de Minas gerais, Faculdade de Filosofia e Ciências Humanas, 2010.

MARX, Karl. O capital: critica da economia política. Tradução de Regis Barbosa e Flávio R. Kothe. São Paulo: Abril Cultural, 1988. (Volume I).

MIZUKAMI, Maria da Graça Nicoletti. Ensino: as abordagens do processo. São Paulo: E.P.U., 2013.

PEREIRA, Agostinho Oli Koppe; HORN, Luiz Fernando Del Rio. Relaçóes de consumo: meio ambiente. Caxias do Sul, RS: Educs, 2009.

ROSSONI, Claudia Regina Rech. Compro, logo existo: a sociedade de consumo no cotidiano escolar. Sorocaba, SP, 2010.

SEVERINO, Antonio Joaquim. Metodologia do Trabalho Científico. São Paulo, SP: Cortez Ed., 2000.

STRAPAZZON, Ironilda; MACHADO, Ana Maria Netto. Como promover autonomia em uma sociedade capitalista regida pelo consumo? Mais uma missão impossível para os educadores? IX ANPED SUL, 2012. 